\title{
LOS JÓVENES Y LA ACCESIBILIDAD A LA VIVIENDA
}

\author{
Paloma Taltavull de La Paz \\ Universidad de Alicante
}

Remisión Artículo: 17-9-2007

Palabras clave: vivienda, accesibilidad.

Resumen: El artículo aborda los problemas relacionados con la accesibilidad a la vivienda de los jóvenes en España. Se remarcan las dificultades ligadas con los mercados de propiedad y alquiler, la situación actual de elevación de coste financiero y precios, así como la relación intensa entre acceso a la vivienda y mercado de trabajo.

El acceso de la vivienda para los jóvenes se ha empeorado de forma relevante desde hace algunos años en España. El problema parece más grave desde hace casi dos, a la vista de las quejas públicas de instituciones y particulares sobre el impacto específico de este problema en el colectivo de jóvenes en España. Sin embargo, es necesario clarificar las razones que tienen los jóvenes a la hora de demandar una vivienda, y la fórmula mediante la que lo hacen, para situar en el marco preciso el problema de falta de viviendas.

\section{Introducción:}

Los jóvenes pueden acceder a una vivienda, al igual que todo el mundo, mediante el alquiler o la propiedad. Si se trata de alquiler, los problemas podrían encontrarse en el ámbito de la oferta, por que no hayan suficientes viviendas en alquiler, o por que las que hay no son acordes con las necesidades de los jóvenes, o en el de los precios, porque los alquileres son tan elevados que desincentivan este sistema de acceso. Si se trata de la propiedad, entonces los problemas pueden venir determinados por lo que se conoce como 'falta de accesibilidad' a la compra, situación que no afecta únicamente a los jóvenes sino también a todos aquellos potenciales demandantes con similares características socioeconómicas.

En este artículo se centra el problema de acceso de los jóvenes, entendiendo como tales a aquellos que están en edad de emancipación y formación de nuevos hogares sometidos a las condiciones laborales vigentes. Se trata, por tanto, de un colectivo que requiere su primera vivienda ${ }^{1}$. Esta característica tampoco es exclusiva de los jóvenes, ya que todo individuo u hogar que migre de su lugar de origen es potencial demandante en estas condiciones.

Si el concepto de joven se diferencia del resto de colectivos en algo, esto es (1) en que están recientemente emancipados y (2) que comienzan su vida laboral. Ambas cosas significan, en primer lugar, que son dependientes del mercado de trabajo y de cómo se produzca el proceso de creación y destrucción del empleo para las cohortes de edad joven, y en segundo, que no tienen seguridad laboral hasta bien avanzados los veinte años, generalmente. Ambas características les dan una debilidad remarcable en cuanto a su posición como demandantes residenciales, ya que, o bien necesitarán una vivienda en alquiler acorde con sus ingresos (bajos), o bien adolecen de la seguridad de ingresos para acceder al crédito hipotecario que les permita comprar una vivienda. Aún en el caso en que sus ingresos les permitiesen pagar las obligaciones derivadas de la hipoteca, su inestabilidad laboral podría hacer que el sistema les

\footnotetext{
${ }^{1}$ Quedan descartadas, por tanto, las demandas de segundas viviendas o de reposición en este análisis.
} 
denegase el crédito, lo que eliminaría, de inmediato, su posibilidad de entrada mediante un mecanismo que es conocido como restricción crediticia. Y aún más, los cambios en la situación del sistema financiero que se están experimentando en el mercado internacional, en términos de riesgos generalizados y mayores tipos de interés, puede añadir un problema adicional que reduzca, aún más, la accesibilidad residencial a estos grupos de población.

En cuanto a la disponibilidad de viviendas en alquiler, las estadísticas españolas muestran como el parque de viviendas tiene una proporción muy pequeña destinada a este fin (del $10.85 \%$ del total de principales, ver cuadro 1 ), por lo que el primer problema, la reducida existencia de oferta, muestra un mercado con pequeño tamaño que incorpora restricciones severas. Por su parte, si se tiene en cuenta que los jóvenes serían los grupos de edad menor de 34 años, los hogares cuya persona de referencia es 'jóven' ocupa una tercera parte del total de viviendas en alquiler (2.98\% del total de principales), mientras solo 1/8 del total de viviendas principales en propiedad.

Tabla 1.- VIVIENDAS SEGÚN LA EDAD DE LA PERSONA DE REFERENCIA

$\%$ s/ total de viviendas principales

\begin{tabular}{|c|c|c|c|c|c|c|}
\hline & $\begin{array}{l}\text { TOTAL } \\
\text { VIVIENDAS } \\
\text { PRINCIPALES }\end{array}$ & 15-19 & $20-24$ & 25-29 & $30-34$ & $\begin{array}{l}\text { TOTAL } \\
\text { JÓVENES }\end{array}$ \\
\hline $\begin{array}{l}\text { En propiedad por compra, totalmente pagada } \\
\text { En propiedad por compra, con pagos pendientes }\end{array}$ & 50,58 & 0,08 & 0,38 & 0,97 & 2,13 & 3,55 \\
\hline (hipotecas...) & 24,14 & 0,04 & 0,39 & 1,93 & 4,16 & 6,53 \\
\hline En propiedad por herencia o donación & 8,16 & 0,01 & 0,08 & 0,25 & 0,52 & 0,85 \\
\hline TOTAL PROPIEDAD & 82,87 & 0,13 & 0,85 & 3,15 & 6,81 & 10,94 \\
\hline En alquiler & 10,85 & 0,07 & 0,47 & 1,02 & 1,42 & 2,98 \\
\hline $\begin{array}{l}\text { Cedida gratis o a bajo precio por otro hogar, la } \\
\text { empresa... }\end{array}$ & 2,48 & 0,01 & 0,08 & 0,21 & 0,38 & 0,69 \\
\hline Otra forma & 3,80 & 0,02 & 0,09 & 0,25 & 0,47 & 0,82 \\
\hline
\end{tabular}

Fte. INE. Censo 2001

La relevancia del alquiler para este grupo la muestra la distribución por edades que se observa en el gráfico 1, donde el uso de las viviendas en alquiler y cedidas por parte de los jóvenes parece ser fundamental en el acceso residencial, antes de 'saltar' a la tenencia en propiedad, a partir de la cohorte de los 30-34 años.

\section{GRAFICO 1}

DISTRIBUCIÓN DE TENENCIA POR EDAD DE LA PERSONA DE REFERENCIA EN EL HOGAR

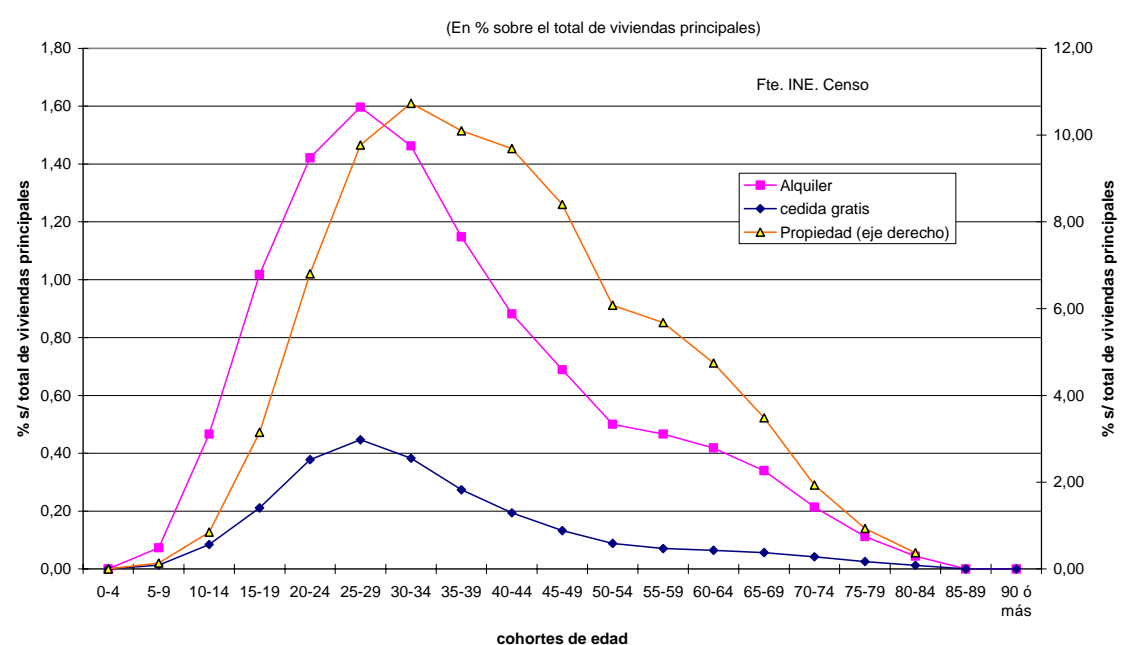


El cuadro 1 es muy significativo sobre donde se encuentra la segunda parte de los problemas de los jóvenes. El $24.14 \%$ de las viviendas principales son tenidas en propiedad y tienen pagos pendientes. Una cuarta parte de ellas están en manos de jóvenes, es decir, el 6.5\% del total de viviendas principales con cargas pertenecen a menores de 34 años (de la persona de referencia del hogar). Si se tiene en cuenta que del total de hogares un $16.7 \%$ tienen jóvenes como persona principal, y de ellos, un $14.3 \%$ están ocupados, podría afirmarse que casi la mitad de los hogares jóvenes propietarios dependen del mercado de trabajo para atender los pagos pendientes por razón de vivienda. Cabría esperar una cantidad mayor porque la proporción de estos hogares sobre el total, dada la relevancia de los estratos de población joven, parece pequeña. Esto dirige hacia dos cuestiones. La primera es que la reducida proporción de hogares jóvenes sobre el total muestra la dificultad de la población española para acceder a una vida independiente en los primeros años desde la edad de emancipación. La segunda es la eventualidad de hacerlo por problemas de accesibilidad, ya que la dependencia del mercado de trabajo determina la posibilidad, o no, de formar un núcleo de convivencia independiente.

El concepto de accesibilidad hace referencia básicamente una forma de medir si una familia en una situación de empleo estable puede o no acceder al mercado de vivienda en propiedad. Se dice que un demandante potencial de viviendas tiene capacidad de acceso cuando sus ingresos están en disposición de atender, con un máximo del $30 \%$ de los mismos ${ }^{2}$, el importe de amortización del crédito hipotecario concedido por la compra de la vivienda. El ratio de accesibilidad es la razón entre el pago por la hipoteca concedida (anual) y los ingresos de la unidad familiar. A su vez, el numerador depende del precio de la vivienda, ya que el importe de la hipoteca es, como máximo, el $80 \%$ del mismo, del tipo de interés existente y de la madurez del préstamo.

$$
\text { acc }=30 \%=c_{h} \text { it } / \text { Ingresos }
$$

Donde $C_{h}$ (función del precio de las viviendas) es el capital concedido en la hipoteca, $i$ es el tipo de interés y $t$ es la madurez del préstamo. La cuota de amortización se calcula teniendo en cuenta los tres componentes. Si los precios residenciales aumentan, $\mathrm{C}_{\mathrm{h}}$ aumenta $\mathrm{y}$, caeteris paribus, el numerador crece y también el ratio de accesibilidad, mostrando una pérdida en la capacidad de acceso de la demanda. Sin embargo, si el tipo de interés disminuye o la madurez crece, es decir, el plazo de pago aumenta, entonces sucede lo contrario.

En el gráfico 2 se observa la evolución de este indicador de accesibilidad en España. Su comportamiento responde al movimiento de los cuatro factores que integran el ratio, y que determinan que los problemas de accesibilidad sean coyunturales. Así pues, y a pesar del fuerte aumento en los precios residenciales que se ha experimentado en España desde 2000, y a la casi estabilización de los ingresos salariales, la accesibilidad en media se ha mantenido en los mínimos históricos durante un largo período de tiempo (desde 1996 hasta 2005). Sin embargo, desde este último año, las condiciones que juegan en este indicador han tendido a empeorar la situación de acceso. El responsable del aumento es fundamentalmente el crecimiento de los tipos de interés, que jugando sobre precios muy elevados y máximos en la concesión hipotecaria, han incrementado mucho la cantidad a pagar como servicio de la deuda hipotecaria. Dado que los ingresos salariales no han crecido a su vez, el ratio de accesibilidad ha tendido a sobrepasar ampliamente el 30\%, estando cercano al $48 \%$ con los últimos datos publicados.

\footnotetext{
${ }^{2}$ Este porcentaje del $30 \%$ se conoce como el ratio crédito-renta. En España suele aplicarse una proporción algo superior, hasta el 35\%, como referencia de accesibilidad plena. Este es el indicador que utilizan las instituciones financieras para determinar la concesión del crédito hipotecario al solicitante, además de otros indicadores de restricción crediticia. Ver Taltavull, 2004
} 
El efecto que este aumento tiene es doble: en primer lugar, limita el acceso al mercado en propiedad de las familias jóvenes (y reduce también la demanda de reposición de las no tan jóvenes), con lo que aquellos hogares en formación dependientes del primer empleo (fijo), se resienten al no alcanzar los mínimos de ingresos necesarios para comprar la vivienda. El ratio del gráfico 2 está calculado teniendo en cuenta solo una persona del hogar que aporte ingresos, por lo que una fórmula que mantenga el acceso para los hogares jóvenes, es decir, para que el crecimiento de la línea azul no afecte a la capacidad de acceso, es que los dos miembros trabajen. Así pues, la dependencia del mercado de trabajo es aún mayor, ya que el acceso residencial se perpetuará en la medida en que se creen suficientes empleos que mantengan la actividad múltiple en los hogares, pero en el momento en que el proceso se invierta, el impacto sobre el acceso puede ser muy relevante.

\section{GRAFICO 2}

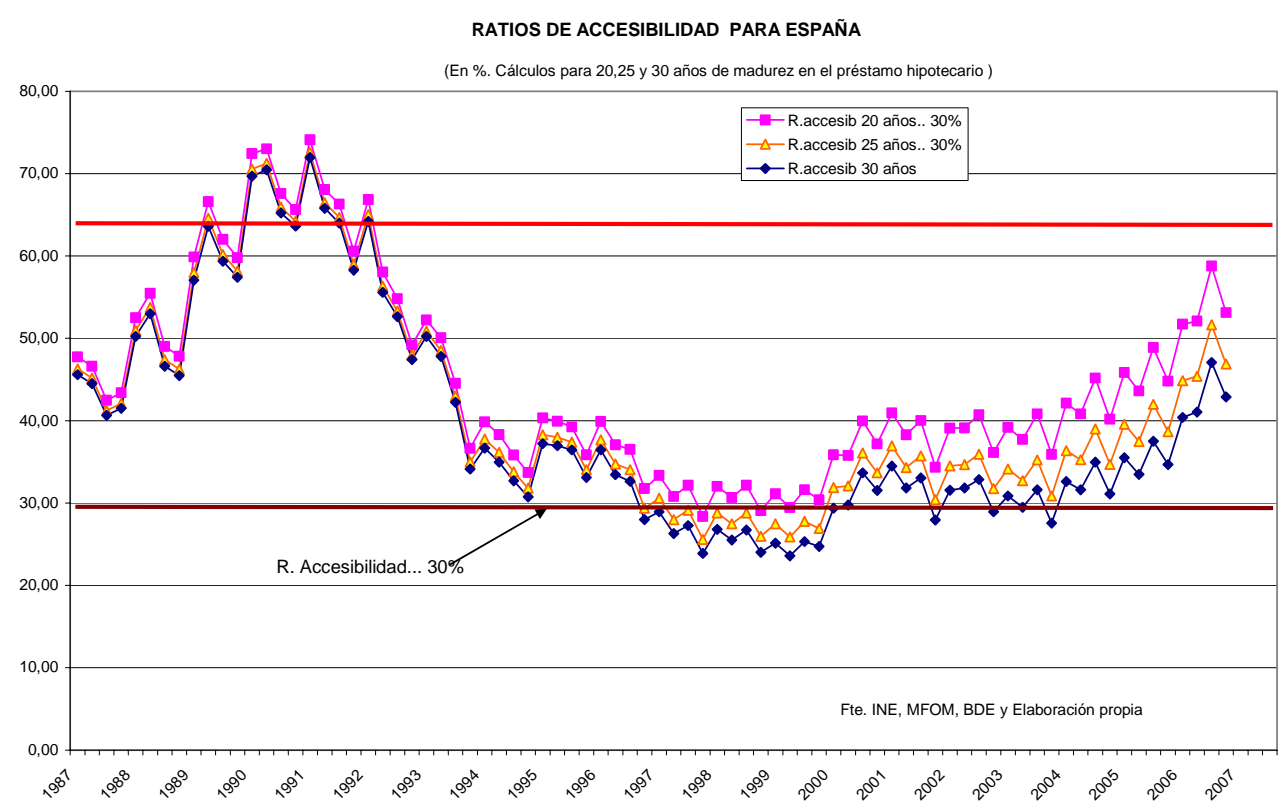

En segundo lugar, la evolución de la accesibilidad también afecta a los hogares jóvenes que han entrado al mercado recientemente. El aumento del coste de la financiación, con hipotecas a tipo variable, produce que los pagos por servicio de la deuda hipotecaria aumenten. En una situación en la que se ha destinado el máximo posible de los ingresos al pago de la cuota, un aumento de ésta genera problemas en los hogares ya endeudados. El resultado de ello redundará en una disminución del consumo (sustitución de gasto) en este grupo de familias en el mejor de los casos, y siempre que se mantengan los ingresos (y los puestos de trabajo).

Este sería el status quo de la situación de los jóvenes en ausencia de otras tensiones. Sin embargo, en los últimos años se han producido cambios en los mercados que han promovido la aparición de mayor flujo de demanda residencial en casi toda España, y que han provocado una competencia por las viviendas, primero en alquiler y después en propiedad. Estos flujos de demanda proceden de los movimientos de población: en primer lugar, internos, con una relocalización de los hogares en España hacia los lugares de mayor ritmo de crecimiento en la actividad económica. En segundo lugar, similares factores han atraído flujos de inmigración extranjera muy fuertes, que han competido, en primer lugar, por las viviendas en alquiler. 
Todos ellos, junto con los jóvenes, se encuentran en la fuente explicativa del aumento de los precios residenciales, y la continuidad en este fenómeno implica que siguen existiendo similares fuerzas que continúan la tendencia. Con esta fortaleza de demanda y su consiguiente aumento en los precios, algunos segmentos abandonan el mercado en propiedad y se dirigen al de alquiler, haciendo crecer, también, la renta en ellos hasta niveles fuera del equilibrio. Con aumentos en los precios en ambos mercados sustitutivos, los jóvenes con menores ingresos encuentran dificultades mayores en entrar en cualquiera de los dos, acrecentándose las dificultades.

Como conclusión, podrían remarcarse algunas características de los problemas que los jóvenes encuentran al entrar en el mercado de viviendas. En primer lugar, la inestabilidad laboral y los ingresos reducidos (así como el retraso en la entrada en el mercado de trabajo) hacen que el acceso a la primera vivienda sea difícil. Lo es en el mercado de alquiler, dada su reducida oferta y la fuerte competencia por las unidades existentes procedentes de los distintos flujos de hogares, que elevan sus rentas y eliminan el stock disponible. También lo es en el mercado de propiedad, dado que los altos precios (a pesar de la flexible oferta en la mayor parte de los territorios de España) y el coste financiero, limitan el ajuste con los ingresos mínimos necesarios para el pago de las hipotecas a los precios vigentes. Sólo los hogares jóvenes con más de un ingreso, o con ayudas familiares, pueden entrar en el mercado. En segundo lugar, las variaciones en el mercado de trabajo y en las condiciones de financiación tienen efectos importantes en los hogares jóvenes que han entrado en el mercado de propiedad o pretenden hacerlo, ya que un incremento en el coste financiero puede hacer superar el límite de pago dados los ingresos disponibles, y un aumento del desempleo puede suponer la imposibilidad de devolver el préstamo.

En esta situación, la política de vivienda tiene un papel relevante, dado que los hogares jóvenes tienen amplio recorrido futuro y su consolidación es fundamental para el mantenimiento de una estructura social duradera. 
Architecture, City, and Environment

Arquitectura, Ciudad y Entorno 